\title{
Implementing Augmented reality in Tourism
}

\author{
Iva Cibilić $^{\mathrm{a}, *}$, Vesna Poslončec-Petrića ${ }^{\mathrm{a}}$, Kristina Tominić ${ }^{\mathrm{b}}$ \\ ${ }^{a}$ Faculty of Geodesy, University of Zagreb, Croatia - iva.cibilic@geof.unizg.hr,vesna.posloncec-petric@geof.unizg.hr \\ ${ }^{b}$ Faculty of Science, Department of Geography, University of Zagreb, Croatia - kristina.tominic@student.geog.pmf.hr \\ * Corresponding author
}

\begin{abstract}
Modern technology is becoming a necessity of many destinations to stay competitive and attractive to the tourist. A new form of technology that is being used increasingly is Virtual and Augmented Reality (AR). The aim of this paper is to display the development of a mobile AR tourism application in urban heritage called PazinAR. Although Augmented Reality has passed the initial hype stage, the technology is just on the verge of being implemented in the tourism industry. This paper describes preparation, design, implementation and execution of prototype touristic application based on Augmented Reality (AR) technology. The application was made using Unity software and AR SDK Vuforia and exported as Android applications. Created application enables overlapping old photos with current view. Furthermore, several significant implications for AR Tourism research and practice are revealed.
\end{abstract}

Keywords: Augmented Reality, tourism, mobile application, Pazin

\section{Introduction}

Technological advances make significant changes in the way we communicate and access information. Hardware is getting smaller and software is becoming more powerful. The consequence is user depending on technology and its involvement in daily activities. There are a growing number of real-world visualization tools using computer programs. Augmented reality has been attracting a lot of attention over the last few years as a technology that has found application in industry, construction, medicine, marketing, computer games, education, tourism. The idea of combining the digital and the real world is exciting because it allows not only the visualization of the non-existent but also the integration of various information simultaneously (Cibilić, I., 2020; Cibilic et al., 2020). Mobile-based virtual experience for the tourism industry has been identified as a potential form to modify current consumers experience (Kalawsky et al., 2000). While users experience a destination with augmented reality applications, they also have the opportunity to explore many features with their imagination. In addition, tourists are provided with more detailed information about their activities in the destinations they visit, and tourists who visit any destination with mobile technology infrastructure benefit from various services through mobile travel guides and location detection. This aspect of tourism is showing great potential in urban and cultural heritage tourism. Whereas museums have already started to preserve media, the approach of pushing information lacks the interactive aspect of tourists and technology. In order to gain a competitive advantage, the use of modern technology is crucial for many destination-marketing organizations. PazinAR was created with the purpose to enrich turistic offer in the city of Pazin and enhance experience to the tourist.

\section{Augmented reality}

Augmented reality (AR) is technology that supplements the real world with virtual, computer-generated objects that appear in the same space as the real world. With new smart technology we are embracing this new and exciting kind of interaction. According to Milgram et. al. (1994) $\mathrm{AR}$ is one part of the general area of mixed reality. Both virtual environments and augmented virtuality replace the surrounding environment by a virtual one. In contrast, AR provides local virtuality.

In order to avoid limiting AR to specific technologies, following three characteristics of augmented reality systems are defined (Azuma, R., 1997): (1) blend real and virtual objects in a real environment; (2) are interactive in real time; (3) align real and virtual objects (e.g. 3D objects) with each other (registered in 3D). Three aspects of this definition are important to mention. Firstly, it is not restricted to display technologies such as a headmounted display (HMD). The definition is not limited to the sense of sight, as AR can and potentially will apply to all senses, including hearing, touch, and smell. Finally, removing real objects by overlaying virtual ones, approaches known as diminished reality, is also considered AR.

\subsection{Augmented reality visualization}

There are basically three ways to visually represent augmented reality (Van Krevelen and Poelman, R. 2010). The first way to augment reality is with a video system a video feed of reality with AR overlaid upon the digitized images. This includes removing or replacing the marker with virtual objects. Another way is to have an optical vision system whose real-world perception is real, with AR displays using transparent mirrors and lenses. It can be applied to head-mounted displays, handheld displays and projectors. Aside from not changing the 
resolution of the real world, they also have the advantage of being parallax free. These techniques are safer because they can be used without the use of electricity, making them an ideal technique for military and medical purposes. Other input devices, such as a camera, are required for interaction and registration. The third approach is to project the AR onto the objects themselves, resulting in projective systems. The advantage of these screens is that they cover large areas for a wide field of view. However, other input devices are required for the interaction. Also, projectors should be calibrated each time the environment or distance to the projection surface changes.

\subsection{Augmented reality devices}

Augmented reality can be experienced through several different displays: head-mounted devices, hand-held displays, and projectors (Van Krevelen and Poelman, R. 2010). Head-mounted devices include a video and optical vision system and projective displays. The current drawback of such devices is that they are limited to their battery life. The main advantage is the fact that the user is not limited to constantly looking at a computer or cellphone screen, as well as being able to use it on the go. Hand-held displays provide video and optical displays as well as handheld projectors. This is currently the best solution for distributing AR to the mass market due to its low cost of production and easy use. This device adjusts the images based on the current orientation of the camera relative to the environment.

The last category of display is statically placed in the environment and includes on-screen video vision systems, spatial optical vision systems and projective displays. This technique is applied in the sports television, where environments such as swimming pools are well-defined and easily augmented. Impressions like those in military training cockpits are becoming a standard extension in the automotive industry to project navigation directions in windshields.

\subsection{Augmented reality in tourism}

The tourism industry has developed throughout the history, mostly in parallel with technology, and has built its activities on attracting the tourists' attention, raising curiosity and meeting the expectations (Ozkul et al., 2019). The developments of information technologies enable destinations to offer new opportunities and activities and provide advantage in competition.

Augmented reality has the potential to improve the tourist experience and help tourists to access relevant information, thus improving their knowledge regarding their touristic destination, while increasing levels of user's entertainment throughout the process (Fritz et al., 2005). Utilization of augmented reality in tourism context proved to be a promising path in several existing papers. Some research on augmented reality in tourism context is focused on usability aspects and cognitive issues (Swan, J.E. and Gabbard, J.L., 2005), but there is also research targeted towards expected user experiences from using augmented reality technology (Olsson, T. and Salo, M., 2011).

Yovcheva et al. (2013) define the augmented tourism experience as a "complex construct which involves the emotions, feelings, knowledge and skills resulting from the perception, processing and interaction with virtual information that is merged with the real physical world surrounding the tourist".

Olsson et al. (2013) documented captivation, motivation, engagement and novelty as some of the more relevant characteristics of expected user experiences with using augmented reality technologies.

Due to the potential of enhancing the immediate surrounding, Augmented Reality has been considered to be of high potential for the tourism industry (Fritz et al., 2005).

It is evident that the number of tourists interested in heritage cities in steadily growing, affecting the tourist experience that destinations have to offer. Vlahakis et al. (2001) discuss the project ARCHEOGUIDE (Augmented Reality-based Cultural Heritage On-site GUIDE) used in the field of cultural heritage by adapting it to tourism. The project provides a personal electronic guide and tour assistant for cultural site visitors in Europe. The application, which provides visitors with cultural data, restoration information, virtual tours, provides a lot of information about archaeological research and cultural tourism to tourists wishing to get information both for entertainment and professional purposes with its multimode user interface.

Just like in the rest of the world, Croatia is following trends with an application of augmented reality in tourism. In the context of this paper, the most important examples of the application of the mentioned technologies in the field of tourism are highlighted.

Barone Fortress in Šibenik, Croatia offers a tour of the authentic location with the help of augmented reality technology. Glasses and a tablet allow the display of historical figures and scenes within the physical world of visitors. Thanks to this project, the Barone Fortress is one of the world's top solutions that create a new generation of museum and cultural tourism products using modern technology (URL1). In February 2017, it received the Grand Prix for the best communication project in the public sector. In May of the same year, it received the European MIXX award in the Virtual category and augmented reality for the project "Storytelling in augmented reality - Fortress Barone".

The project "3D AR Virtual Portal" in Šibenik brought the prestigious world award for innovation in tourism Ulysses in 2013 (URL2). It works in a way that the mobile device is directed towards the statue of Juraj Dalmatinac in the main square in Šibenik, who then comes to life on the screen of the device and starts with a story about the cathedral and its construction and takes the visitor for a walk through the location.

Another example is the Zagreb Time Travel application (Fig.1), which presents the city's sights as a journey 
through time (URL3). With the tablet application, visitors can see a computer-generated guide, famous persons from history telling a story about specific sight. In addition to guides, certain films and scenes from the past are shown on the locations, there is a possibility of solving crossword puzzles and riddles and using various filters.

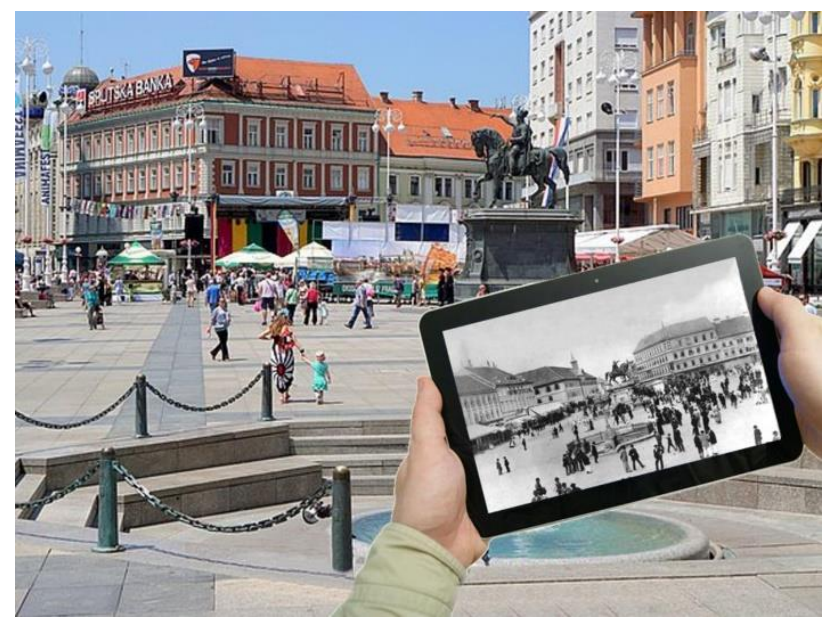

Figure 1. Display of Zagreb Time travel application (URL3)

The application PazinAR should enrich the touristic offer of the city of Pazin through a visual sensation. The application would be applied to specific locations where it would use a smartphone camera to display the architecture and appearance of the city in the past.

\section{PazinAR}

There are two basic views that the application should recognize: the real world and the picture of the current location in the past. First, it was necessary to collect the old pictures of the city. Although no conditions were set for the date of the photographs, it was necessary to pay attention on two important things. Pictures must be in digital form and have good resolution, should not be damaged and the environment should be clearly shown. Furthermore, a lot of attention was focused on the position in which the photographs was taken. Numerous photographs have been taken in places that do not exist or cannot be reached due to changes in the natural and cultural landscape over time. Since the old photo needs to fit and (somewhat) overlap with the real environment, the shooting angle and position are important. Figures $2-4$ display pictures used in the implementation of the PazinAR application. Figures were found in the Facebook group called „Domaće beside s Pazina i okolice“.

The goal of PazinAR project was to develop interactive tour guide through the city of Pazin to enrich tourist offer in the city. The program in which the application was created is Unity, and for augmented reality features, a Vuforia SDK has been added to it. The application is installed on the ASUS ZenBook 14 smartphone and has all the features tested. Marker recognition was tested with a positive result (Tominić, K., 2021).

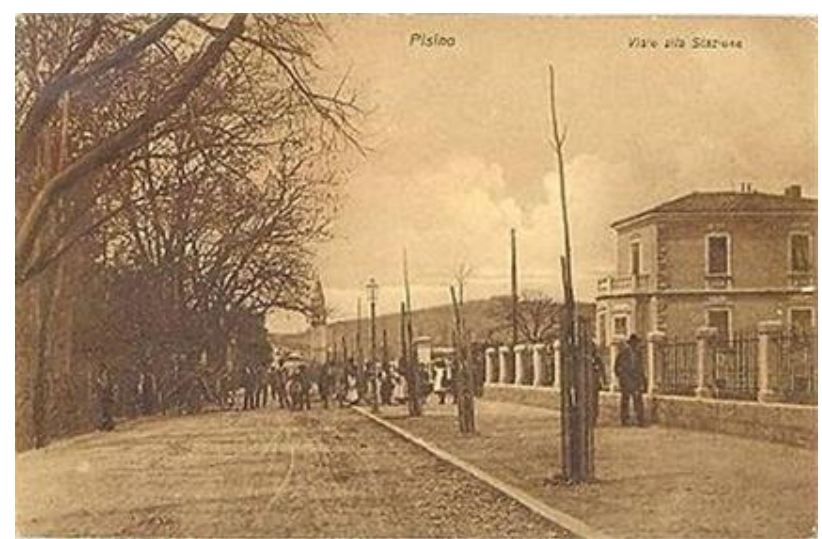

Figure 2. Promenade in Pazin, year unknown (URL4)

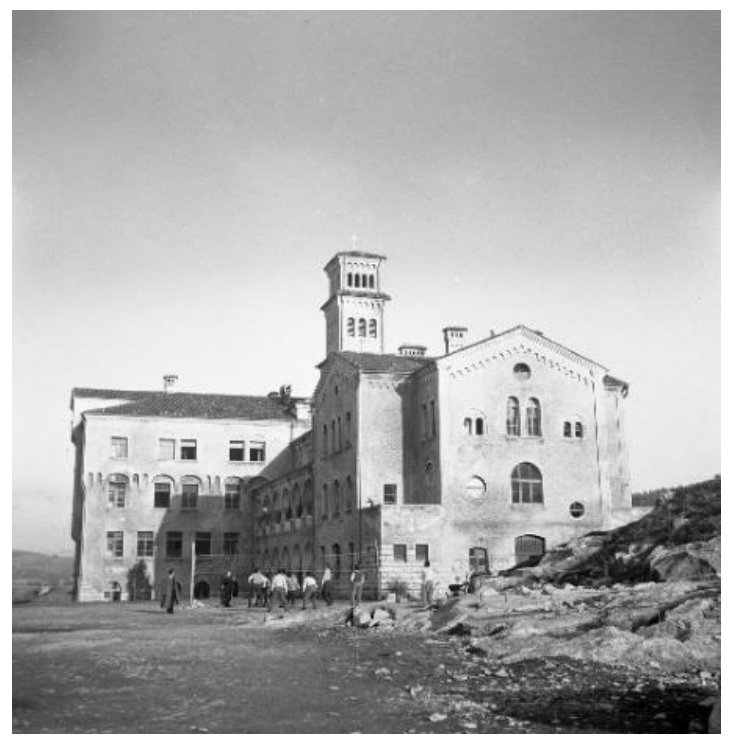

Figure 3. Pazin university, 1905. (URL5)

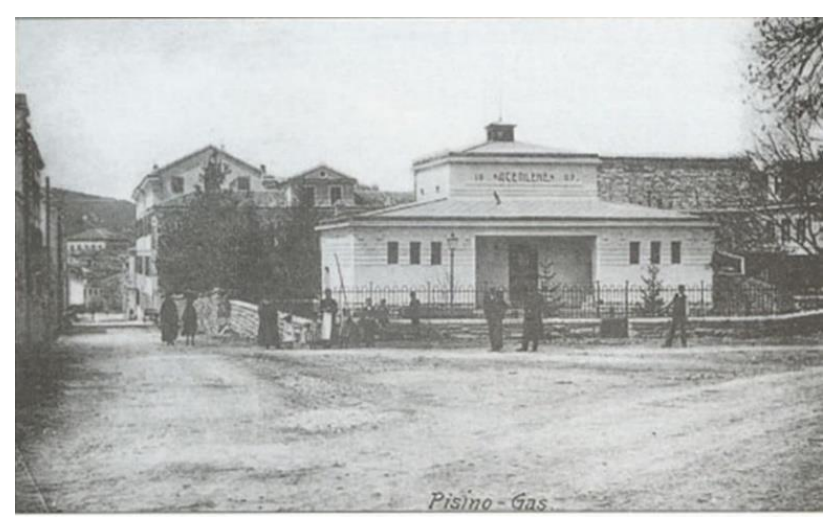

Figure 4. Former gas station, 1911. (URL6)

The process of displaying the augmented reality content includes the following steps: first the camera shows the actual environment, then the system's algorithm captures video images and creates a pattern, the pattern is compared with a sample from the database, and if the system finds similarity, displays and positions the content depending on the sample (marker). In order to use the system smart device should have an application installed. Figures 5-7 display a screen of the application with old photos aligned with real world environment. 


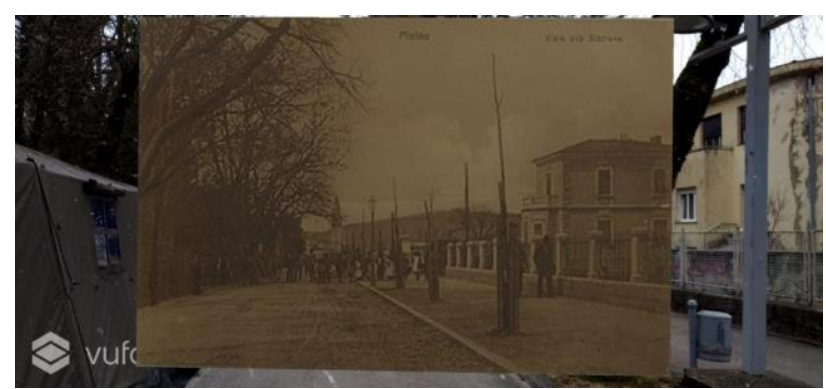

Figure 5. Screenshot of the ASUS ZenBook 14 smartphone when using the PazinAR at the Pazin Promenade location

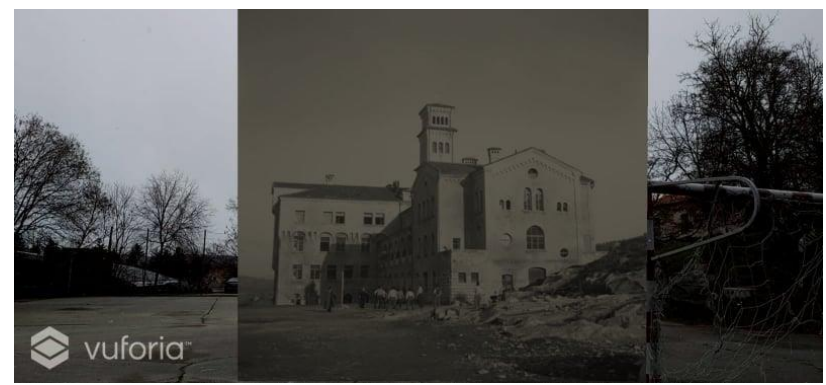

Figure 6. Screenshot of the ASUS ZenBook 14 smartphone when using the PazinAR at the Pazin university location

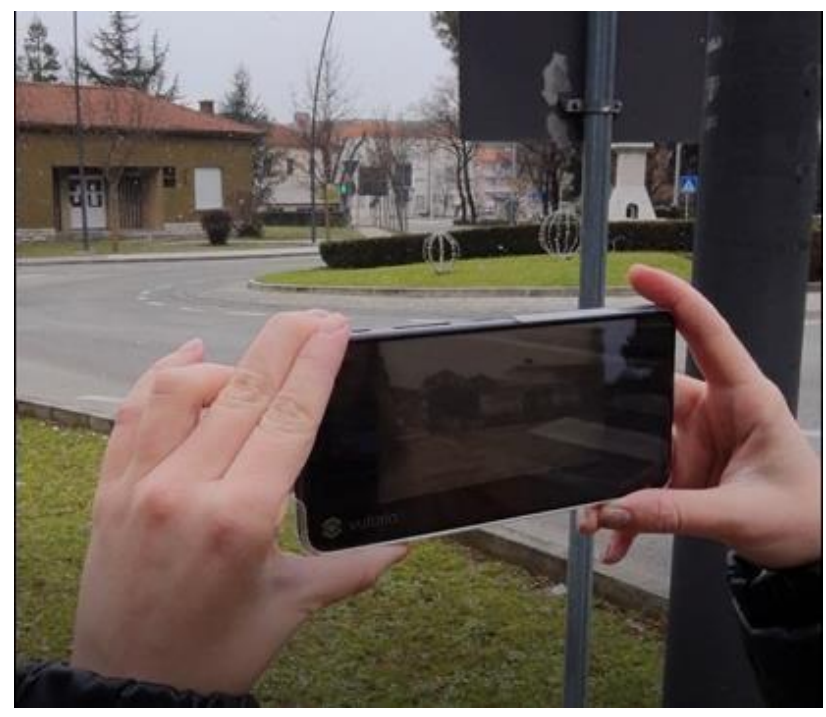

Figure 7. Screenshot of the ASUS ZenBook 14 smartphone when using the PazinAR at the Former gas station location.

\section{Conclusion}

AR applications offer unknown regions as tourism activities in a fun and interactive way in order to stay competitive and attractive for tourists. Created application can provide to touristic offer in Istria, especially the city of Pazin. It is anticipated that many enterprises operating in tourism sector will benefit from the applications in order to provide satisfaction and create a competitive advantage comparing to the other enterprises in the future. Current implementations of AR in tourism lack effective engagement of the user and provide an enhanced experience to the tourist. Furthermore, it has not yet been made flawless, and includes many bugs, which need to be overcome before offering it to the public. Nonetheless, Augmented Reality shows high potential in becoming a main-stream technological tool in tourism in the near future due to its practical usefulness.

\section{References}

Azuma, R. (1997). A Survey of Augmented Reality. Presence: Hughes Research Laboratories, 6(4), 355-85.

Cibilić, I. (2020): Augmented reality navigation, Master thesis, University of Zagreb, Faculty of Geodesy Zagreb

Cibilić, I., Vuković, V. and Poslončec- Petrić, V. (2020) Augmented Reality app - exploring and wayfinding around Faculty. U: Kopačik, A., Kyrinovič, P., Erdelyi, J., Paar, R. \& Marendić, A. (ur.) INGEO\&SIG 2020 Proceedings of the 8th International Conference on Engineering Surveying 4th Symposium on Engineering Geodesy.

Fritz, F., Susperregui, A. and Linaza, M.T. (2005). Enhancing cultural tourism experiences with augmented reality technologies. 6th International Symposium on Virtual Reality, Archaeology and Cultural Heritage (VAST).

Kalawsky, R.S., Stedmon, A.W., Hill, K. and Cook, C.A. (2000). Old Theories, New Technologies: Developing Guidelines for the Cognitive Ergonomics of Augmented Reality. Proceedings of the Human Factors and Ergonomics Society Annual Meeting, 44, 3-398.

Milgram, P., Takemura, H., Utsumi, A., Kishino, F. (1994). Augmented Reality: A class of displays on the reality-virtuality continuum. SPIE Vol. 2351, Telemanipulator and Telepresence Technologies, 282292.

Olsson, T. and Salo, M. (2011). Online user survey on current mobile augmented reality applications. In 10th IEEE International Symposium on Mixed and Augmented Reality (ISMAR). IEEE.

Olsson, T.; Lagerstam, E.; Kärkkäinen, T. and VäänänenVainio-Mattila, K. (2013). Expected user experience of mobile augmented reality services: a user study in the context of shopping centres. Personal and ubiquitous computing 17(2), 287-304, 2013, http://dx.doi.org/10.1007/s00779-011-0494-x

Ozkul, Emrah \& Kumlu, Sarp. (2019). Augmented Reality Applications in Tourism. International Journal of Contemporary Tourism Research. 107-122. 10.30625/ijctr.625192.

Swan, J.E. and Gabbard, J.L. (2005). Survey of userbased experimentation in augmented reality. Proceedings of 1st International Conference on Virtual Reality.

Tominić, K. (2021). Development of the application "Pazin AP". Seminar paper from the course Practical Cartography. University of Zagreb, Faculty of Geodesy.

Van Krevelen, R., Poelman, R. (2010). A Survey of Augmented Reality Technologies, Applications and 
Limitations. The International Journal of Virtual Reality, 9(2):1-20.

Vlahakis, V., Karigiannis, J., Tsotros, M., Gounaris, M., Almeida, L., Stricker, D., ... and Ioannidis, N. (2001). Archeoguide: first results of an augmented reality, mobile computing system in cultural heritage sites. Virtual Reality, Archeology, and Cultural Heritage, 131-140.

Yovcheva, Z.; Buhalis, D. and Gatzidis, C. (2013). Engineering augmented tourism experiences. In Information and communication technologies in tourism. Springer Berlin Heidelberg. http://dx.doi.org/10.1007/978-3-642-36309-2_3

URL1: Barone Fortress. https://www.tvrdjavakulture.hr/en/ (18.3.2021.)

URL2: 3D AR Virtual Portal. https://www.sibenik.in/ (18.3.2021.)

URL3: Zagreb Time Travel. https://zagrebtimetravel.com/ (18.3.2021.)

URL4: Facebook. https://www.facebook.com/photo?fbid=2187090168071 262\&set=g.1171557652948858 (18.3.2021.)

URL5: Facebook. https://www.facebook.com/photo?fbid=3561665357181 360\&set=g.1171557652948858 (18.3.2021.)

URL6: Facebook. https://www.facebook.com/photo?fbid=2130311287082 484\&set=g.1171557652948858 (18.3.2021.) 